\title{
DESEMPENHO DO PROGRAMA FÚNGICO DA SYNGENTA PARA O CONTROLE DE DOENÇAS NA CULTURA DA SOJA
}

Joaquim Júlio de Almeida Júnior ${ }^{1}$ Francisco Solano Araújo Matos ${ }^{2}$, Katya Bonfim Ataides Smiljanic ${ }^{3}$, Beatriz Campos Miranda ${ }^{4}$, Muryllo Cândido Ferreira ${ }^{5}$

1 Pós doutorando, UC - Universidade de Coimbra, joaquimjuliojr@gmail.com. Coimbra, Portugal.

2 Professor Adjunto, Mestre em Fitopatologia. UniFimes-Centro Universitário de Mineiros; Goiás. Brasil.

3 Professora Adjunto, Mestre em Botânica. UniFimes-Centro Universitário de Mineiros; Goiás. Brasil.

4 Acadêmica do curso de Engenharia Florestal. UniFimes-Centro Universitário de Mineiros. Goiás. Brasil.

5 Acadêmico do curso de Agronomia. UniFimes-Centro Universitário de Mineiros. Goiás. Brasil.

\section{Recebido em: 06/04/2019 - Aprovado em: 10/06/2019 - Publicado em: 30/06/2019 DOI: 10.18677/EnciBio_2019A111}

\begin{abstract}
RESUMO
As doenças que ocorrem na cultura da soja propiciam as principais ameaças a produtividade a nível nacional e internacional. O experimento foi conduzido pelo Núcleo de Estudo e Pesquisa em Fitotecnia no município de Jataí, Estado de Goiás. A área experimental foi instalada em uma lavoura comercial de soja cultivar Ponta IPRO. Este trabalho objetivou avaliar a performance do programa de proteção química recomendado pela Syngenta "(Elatus + Cypress + Ochima) > (Cypress + Bravonil 500) > (Cypress + Bravonil 500) com adjuvante Ochima" comparado a programas de proteção comumente utilizado pelo agricultor do Sudoeste de Goiás, como os seguintes fungicidas "Orkestra, Fox e Ativus" e diferentes adjuvantes "Assist, Aureo e FT max" no mesmo estádio de aplicação. As variáveis tecnológicas mensuradas foram: Altura de plantas, Altura de inserção de primeira vagem, Número de vagens por planta, Peso de mil grãos, Produtividade em quilograma por hectare, População de plantas final por hectare. O delineamento experimental foi em blocos casualizados com quatro repetições em esquema $4 \times 3 \times 1$. O programa de proteção fungicida com a sequência de pulverizações: (Elatus + Cypress + Ochima) > (Cypress + Bravonil 500) > (Cypress + Bravonil 500) com adjuvante Ochima, proporcionaram maiores rendimentos de grãos e maiores eficiências de controle de doenças de final de ciclo (DFC) (Cercospora kikuchi e Septoria glycines) e de ferrugem asiática da soja (FAS) (Phakopsora pachyrhizi).
\end{abstract}

PALAVRAS-CHAVE: Controle de pragas. Fitossanitários. Glycine max. Produtividade 


\title{
PERFORMANCE OF THE SYNGENTA FUNGAL'S PROGRAM FOR THE CONTROL OF DISEASES IN SOYBEAN CROPS
}

\begin{abstract}
The diseases that occur in the soybean crop provide the main threats to productivity at national and international levels. The experiment was conducted by the Research and Phytochemical Research Center in the city of Jataí, State of Goiás. The experimental area was installed in a commercial crop of soybean cultivar Ponta IPRO. This work aimed to evaluate the performance of the chemical protection program recommended by Syngenta (Elatus + Cypress + Ochima) $>$ (Cypress + Bravonil 500)> (Cypress + Bravonil 500) with Ochima adjuvant "compared to protection programs commonly used by the farmer, and the following "Assist, Aureo and FT max" adjuvants were applied at the same application stage, with the following variables: Plant height, First pod insertion height, Number of grains per plant, weight of one thousand grains, productivity in kilograms per hectare, final plant population per hectare The experimental design was in a randomized block with four replicates in a $4 \times 3 \times 1$ scheme The fungicide protection program with the spray sequence: (Elatus + Cypress + Ochima) (Cypress + Bravonil 500) $>$ (Cypress + Bravonil 500) with Ochima adjuvant, provided higher yields (Cercospora kikuchi and Septoria glycines) and Asian soybean rust (FAS) (Phakopsora pachyrhizi).
\end{abstract}

KEYWORDS: Pest control. Phytosanitary products. Glycine max. Productivity

\section{INTRODUÇÃO}

A soja (Glycine max L.) é uma espécie originária da China, pertencente à família Fabaceae, de grande importância para o agronegócio. O Brasil é um dos maiores produtores de soja do mundo, com expectativa da ampliação da área plantada para a safra 2018/2019 com abertura de novas fronteiras agrícolas e o uso de tecnologias disponíveis na atualidade (CONAB, 2019).

As doenças que ocorrem na cultura da soja propiciam as principais ameaças a produtividade a nível nacional e internacional. Estima-se perdas anuais de $15 \%$ a $20 \%$ (GODOY et al., 2016). O uso de fungicidas no controle de DFC's teve início por volta de 1996/1997. Com um aumento do índice de doenças de final de ciclo (Septoria glycines e Cercospora kikuchii), em função do plantio intensivo e ausência na rotação e também a falta de fungicidas registrados para uso na cultura (GODOY et al., 2016). No advento da ferrugem asiática (Phakopsora pachyrhizi) no Brasil no ano de 2001, foram necessários o surgimento de novos produtos. Dentre estas doenças já citadas pode-se destacar outras doenças como a mancha-alvo (Corynespora cassiicola), a antracnose (Colletotrichum truncatum), o mofo-branco (Sclerotinia sclerotiorum) e a mela (Rhizoctonia solani).

Porém, os produtores de soja enfrentam a cada safra, vários fatores que podem levar a redução da produção, afetar a qualidade dos grãos e aumentar os custos. Entre estes fatores estão as doenças causadas por fungos que são favorecidas pelas condições climáticas como temperaturas altas e umidade além de da prática da monocultura. São comuns em áreas com plantio de soja o surgimento de doenças de final de ciclo (DFC) causadas pelo complexo de patógenos Septoria glycines e ou Cercospora kikuchi, a ferrugem asiática da soja (FAS), causada por Phakopsora pachyrhizi e a antracnose na folha e na vagem causada por Colletotrichum truncatum (GODOY et al., 2016). 
De acordo com a Embrapa (2013a) as DFC e FAS podem levar a redução da produção em mais de $20 \%$ necessitando de manejo adequado e medidas de controle que sejam eficientes. A ferrugem asiática (Phakopsora pachyrhizi Syd. \& P.Syd) é caracterizada por saliências que surgem na superfície das folhas denominadas urédias, que representam as estruturas reprodutivas dos fungos. Como medidas sanitárias que visam reduzir os riscos de danos a cultura recomendase o uso de cultivares com ciclo precoce, eliminação de plantas de soja voluntárias, respeito ao vazio sanitário, monitoramento constante da lavoura e o uso de fungicidas específicos quando necessário e as condições ambientais permitirem (YORINORI et al., 2003).

Quanto as doenças de final de ciclo (DFC) são importantes pois vão se manifestar na planta em momentos de enchimento de grãos comprometendo qualitativamente a produção. A cercospora (Cercospora kikuchii) pode ser identificada pelo surgimento de pontos de coloração castanho-avermelhadas que evoluem para uma cor púrpura-escura em toda extensão da folha, que em seguida ocasiona a sua perda em um fenômeno denominado de desfolha (EMBRAPA, 2013a).

A mancha parda (Septoria glycines) se manifesta em pequenas pontuações de cor parda que evoluem para manchas maiores de contornos angulares envolvidas por halos amarelados que podem recobrir toda a superfície da folha. $\mathrm{Na}$ superfície adaxial a coloração das manchas é parda enquanto que na superfície abaxial são rosadas. A infecção severa culmina na desfolha e maturação prematura e consequente redução da produtividade (EMBRAPA, 2013a).

A antracnose (Colletotrichum truncatum) tem como principal sintoma a necrose que pode se manifestar em todos os estádios de desenvolvimento da planta (estádios vegetativos e reprodutivos) e em todos os órgãos (cotilédones, pecíolos, folhas, hastes e vagens). Nas plantas desenvolvidas leva ao estrangulamento e necrose dos pecíolos, nervuras, pedúnculo, hastes, vagens e a desfolha precoce com comprometimento da formação das vagens que podem até serem perdidas (GRIGOLLI, 2018).

Este trabalho objetivou avaliar a performance do programa de proteção química recomendado pela Syngenta "(Elatus + Cypress + Ochima) $>$ (Cypress + Bravonil 500) > (Cypress + Bravonil 500) com adjuvante Ochima" comparado a programas de proteção comumente utilizado pelo agricultor do Sudoeste de Goiás, como os seguintes fungicidas "Orkestra, Fox e Ativus" e diferentes adjuvantes "Assist, Aureo e FT max" no mesmo estádio de aplicação.

\section{MATERIAL E METODOS}

O experimento foi conduzido pelo Núcleo de Estudo e Pesquisa em Fitotecnia no município de Jataí, Estado de Goiás, em área experimental com as seguintes coordenadas geográficas de referência: latitude sul 17²52'44.74" e longitude oeste $51^{\circ} 45^{\prime} 36.01^{\prime \prime}$.

A área experimental foi instalada em uma lavoura comercial de soja cultivar Ponta IPRO semeada em 25 de outubro de 2018. Foi utilizado o fertilizante mineral na formulação 02-20-18 para todas as parcelas experimentais e as aplicações de fungicidas foram efetuadas de acordo com cada tratamento previamente estabelecido (Tabela 2). Os outros manejos fitossanitários foram igualmente aplicados para toda a área de forma que a produção de grãos fosse afetada 
somente pela maior ou menor eficiência de controle de doenças produzidas pelos tratamentos com fungicidas.

A região possui clima classificado por Köppen (2013) tipo Aw, tropical úmido, definido em duas estações, verão chuvoso úmido e inverno muito seco. $O$ índice pluviométrico anual fica em torno de uma média anual de 1.910 milímetros, tendo uma média de temperatura anual próximo dos $25^{\circ} \mathrm{C}$ e média de $67 \%$ de umidade do ar relativa (Figura 1). As predominâncias das chuvas ocorrem nos meses de outubro até março, com uma média acentuada de chuva, isto é, um maior volume de chuva nos meses de dezembro até fevereiro, e no anverso, isto é, o período que ocorre o menor índice de chuva, se encontra nos meses de junho até agosto com uma média de 28 milímetros.

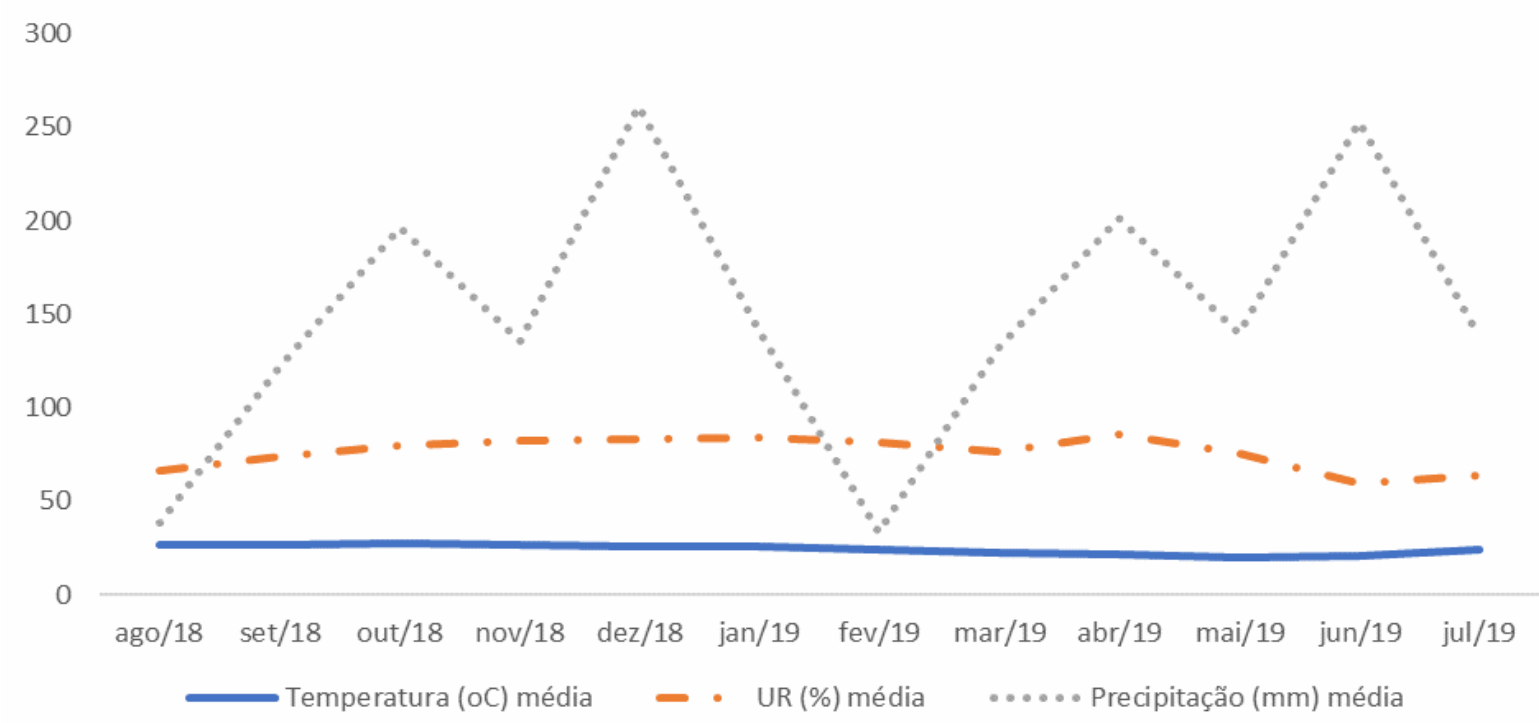

FIGURA 1. Temperatura máxima $\left({ }^{\circ} \mathrm{C}\right)$ médias mensais, umidade relativa do ar $(\%)$ e precipitação pluvial (mm) acumuladas na safra 2018/2019 na área experimental, conduzido pelo Núcleo de Estudo e Pesquisa em Fitotecnia, instalada em uma lavoura comercial de Soja, cultivar Ponta IPRO Jataí. Estado de Goiás. Safra 2018/2019.

FONTE: AGRITEMPO - Sistema de Monitoramento Agrometeorológico Jataí / INMET. Município de Jatai, Estado de Goiás. 2018.

A predominância do solo na área experimental indicado pelo Sistema Brasileiro de Classificação de Solo (EMBRAPA, 2013b) é do tipo Neossolo Quartzarênico, com uma textura baseada em areia, nos plantios passados a ocupação era de vegetação predominante de Cerrado e foi trabalhada por culturas perenes por volta de 16 anos.

O solo possui atributos que foram avaliados para implantação da pesquisa no intuito de observar as características física e química da área experimental. Nestas análises foram determinados $\mathrm{pH}, \mathrm{P}, \mathrm{K}, \mathrm{Ca}, \mathrm{Mg}, \mathrm{H}+\mathrm{Al}, \mathrm{Al}, \mathrm{S} . \mathrm{B}, \mathrm{V}(\%)$ e M.O. entre as profundidades de zero a 20 centímetros e de 20 a 40 centímetros de profundidades (RAlJ et al.,1983). As amostras do solo foram analisadas no laboratório de solo da instituição de ensino de Mineiros, Estado de Goiás (Tabela 1). 
TABELA 1. Resultados obtidos na análise química do solo de amostras coletadas na área experimental instalada em uma lavoura comercial de Soja, cultivar Ponta IPRO em trabalho conduzido pelo Núcleo de Estudo e Pesquisa em Fitotecnia. Jataí. Estado de Goiás. Safra 2018/2019.

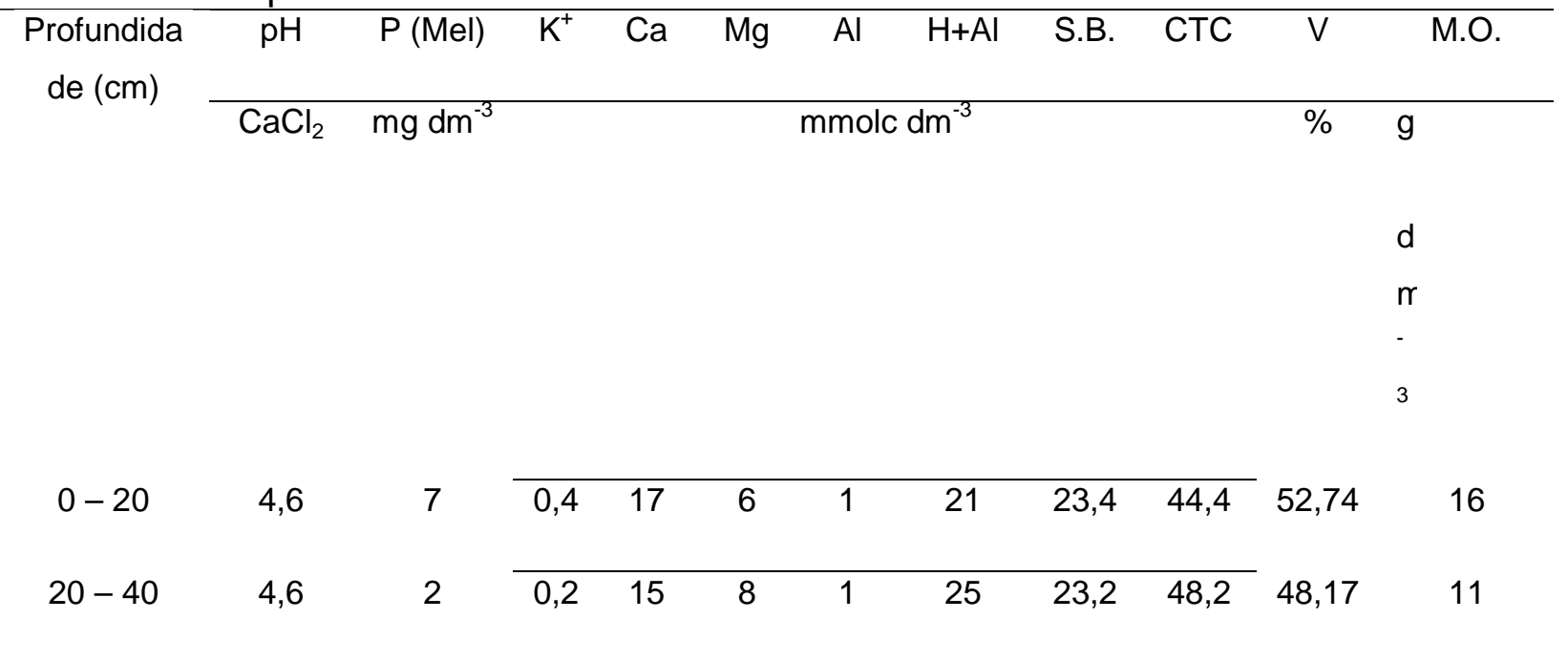

FONTE: Dados da pesquisa, 2019.

O delineamento experimental foi em blocos casualizados com quatro repetições, em esquema $4 \times 3 \times 1$ com quatro tratamentos, três épocas de aplicação e uma variedade de soja. A parcela experimental foi constituída de uma área com 3 metros de largura (aproximadamente seis linhas de plantio espaçadas de 0,45 metros) por 7 metros de comprimento. $\mathrm{Na}$ área central da parcela, constituída de 1 metro (duas fileiras centrais) por 5 metros $\left(5 \mathrm{~m}^{2}\right)$, foram tomados os dados de severidade de doenças e de produção.

Os tratamentos consistiram da combinação de um programa padrão de aplicação de fungicidas, repetido em todos os tratamentos, associados a aplicações de diferentes fertilizantes. No programa padrão utilizou-se três aplicações de fungicidas recomendados para as doenças prevalentes no Sudoeste de Goiás. Estes fungicidas foram aplicados nos estádios: R2 (plantas no reprodutivo- floração plena); R.5.1 (reprodutivo- fase inicial de enchimento de grãos) e R.5.3 (fase reprodutivaenchimento de grão de 50 a 70\%). Utilizou-se as marcas comerciais (MC) de fungicidas e doses: 1) Estádio Vegetativo-Orkestra $(0,3 \mathrm{~L})$; 2) Estagio ReprodutivoElatus + Cypress + FT Max (0,2 L+ 0,3L + 0,1 L); 3) Enchimento de grãos - Ativum + FT Max $-(0,8 L+0,2 L)$. As descrições completas dos tratamentos estão descritas na (Tabela 2).

TABELA 2. Descrição dos tratamentos utilizado na área experimental conduzida pelo Núcleo de Estudo e Pesquisa em Fitotecnia, instalada em uma 
lavoura comercial de Soja, cultivar Ponta IPRO. Jataí. Estado de Goiás. Safra 2018/2019.

\begin{tabular}{|c|c|c|c|c|c|c|}
\hline TRAT & EA & DA & Fungicidas & $\begin{array}{l}\text { Dose p.c.L ha } \\
\end{array}$ & $\begin{array}{l}\text { Adjuvant } \\
\mathrm{e}\end{array}$ & $\underset{1}{\text { Dose p.c.L ha }}$ \\
\hline 1 & R.2 & $\begin{array}{l}07-12- \\
18\end{array}$ & - & - & - & - \\
\hline 1 & R.5.1 & $\begin{array}{l}26-12- \\
18\end{array}$ & - & - & - & - \\
\hline 1 & R.5.3 & $\begin{array}{l}10-01- \\
19\end{array}$ & - & - & - & - \\
\hline 2 & R.2 & $\begin{array}{l}07-12- \\
18\end{array}$ & Orkestra & 0,300 & Assist & 0,300 \\
\hline 2 & R.5.1 & $\begin{array}{l}26-12- \\
18\end{array}$ & Fox & 0,400 & Aureo & 0,100 \\
\hline 2 & R.5.3 & $\begin{array}{l}10-01- \\
19\end{array}$ & Ativum & 0,800 & FT Max & 0,150 \\
\hline 3 & R.2 & $\begin{array}{l}07-12- \\
18\end{array}$ & Elatus+Cypress & $0,2+0,3$ & Ochima & 0,250 \\
\hline 3 & R.5.1 & $\begin{array}{l}26-12- \\
18\end{array}$ & Fox & 0,400 & Aureo & 0,100 \\
\hline 3 & R.5.3 & $\begin{array}{l}10-01- \\
19\end{array}$ & Ativum & 0,800 & FT Max & 0,150 \\
\hline 4 & R.2 & $\begin{array}{l}07-12- \\
18\end{array}$ & Elatus+Cypress & $0,2+0,3$ & Ochima & 0,250 \\
\hline 4 & R.5.1 & $\begin{array}{l}26-12- \\
18\end{array}$ & $\begin{array}{l}\text { Cypress+Bravonil } \\
500\end{array}$ & $0,5+0,3$ & - & - \\
\hline 4 & R.5.3 & $\begin{array}{l}10-01- \\
19\end{array}$ & $\begin{array}{l}\text { Cypress+Bravonil } \\
500\end{array}$ & $0,3+1,5$ & - & - \\
\hline
\end{tabular}

TRAT: Tratamentos utilizado; EA: Estádio de aplicação; DA: Dia da aplicação; Estágios de aplicação dos produtos: R2 (plantas no reprodutivo- floração plena); R.5.1 (reprodutivo- fase inicial de enchimento de grãos) e R.5.3 (fase reprodutiva- enchimento de grão de 50 a 70\%)

FONTE: Dados da pesquisa, 2019.

Para as pulverizações foi utilizado um equipamento costal movido a $\mathrm{CO}^{2} \mathrm{e}$ calibrado para uma vazão de 150 litros de calda por hectare. As pulverizações foram iniciadas sempre no início da manhã, sob condições de temperatura, umidade relativa do ar e ventos, adequadas para que maior quantidade de fungicida atinja a superfície foliar alvo da aplicação.

As avaliações para a quantificação das doenças foram feitas utilizando parâmetros relativos à incidência e severidade de doenças. O nível de doenças foi avaliado em cada parcela experimental amostrando-se quatro plantas escolhidas ao acaso. Em cada planta foi avaliada a folha baixeira, a folha do terço médio e a folha apical. A severidade e a incidência das doenças foram representadas pela média das leituras efetuadas em 12 folhas tomadas de quatro plantas. As leituras de doenças foram efetuadas no campo ou em folhas destacadas e observadas sob microscópio estereoscópio (lupa). A leitura de severidade foi efetuada com o auxílio 
de escalas diagramáticas específicas para cada doença. Para as doenças ferrugem asiática da soja (FAS) (Phakopsora pachyrhizi) e doenças de final de ciclo (DFC) (Cercospora kikuchi e Septoria glycines) utilizou-se parâmetro relativos à severidade, enquanto para a antracnose foliar foi avaliado a incidência da doença.

Para a avaliação da ferrugem asiática da soja (Phakopsora pachyrhizı) foi utilizada uma escala diagramática com as seguintes representações de áreas foliares infectadas (\%AFI): 0,6\%- 2,0\%-7,0\%-18,0\%-42,0\%-78,5\% AFI, conforme escala proposta por Godoy et al., (2006).

Para a avaliação das doenças de final de ciclo (DFC) causadas por (Cercospora kikuchi) e (Septoria glycines) foi utilizada uma escala diagramática com os níveis: $0 \%$; $2,4 \% ; 15,2 \% ; 25,9 \% ; 40,5 \%$ e $66,6 \%$ (AFI) conforme proposto por Soares et al. (2009).

Para a avaliação da incidência de antracnose foram tomadas a mesma amostra de folhas utilizadas para as leituras de severidade de outras doenças (FAS, DFC). Para a contagem de folhas afetadas pela antracnose foi considerada a presença de folhas com sintomas de necrose na nervura. A incidência de folhas com sintomas foi analisada em 12 folhas por parcela.

A avaliação da desfolha causada por doenças foi realizada utilizando-se uma escala diagramática com os níveis de $100 \% ; 85 \% ; 65 \% ; 45 \% ; 15 \%$ e $5 \%$ de desfolha conforme proposto por Hirano et al. (2010). A percentagem de desfolha foi obtida estimando-se uma nota representativa da parcela como um todo.

Os parâmetros produtivos (produtividade e peso de mil grãos) foram obtidos na fase de colheita. Para a população final de plantas foram contadas todas as plantas da área útil da parcela $\left(0,9 \times 5 \mathrm{~m}=4,5 \mathrm{~m}^{2}\right)$. Os grãos de soja foram colhidos e secos ao sol de modo a reduzir e uniformizar as possíveis diferenças de umidades entre as parcelas. As alturas de plantas e da primeira vagem e o número de vagens por planta foram obtidas a partir das medições em 3 plantas por parcela.

\section{RESULTADOS E DISCUSSÃO}

As variáveis tecnológicas altura de planta, altura de inserção de primeira vagem, número de vagens por planta e população de plantas final (Tabela 3) não apresentaram diferença significativa entre os tratamentos utilizados. Resultados semelhantes foram encontrados em trabalho realizado por Matos et al. (2017).

Para a variável tecnológica de produtividade em quilogramas por hectare foi detectada diferença significativa entre os tratamentos. $O$ tratamento sem aplicação de fungicida (T01), registrou a menor produtividade com uma média de $3.318 \mathrm{Kg} \mathrm{ha}^{-}$ 1. Os tratamentos com diferentes programas de proteção com fungicidas apresentaram produtividades entre $3.438 \mathrm{Kg} \mathrm{ha}^{-1}$ (T03) e $3.672 \mathrm{Kg} \mathrm{ha}^{-1}$ (T4) sendo que o tratamento T04, registrou uma produtividade relativa de $10,6 \%$ a mais, superando em $354 \mathrm{Kg}^{-1}$ quando comparado ao tratamento controle T01 (Tabela 3). Em trabalho realizado por Godoy et al., (2009) com a mistura de $60 \mathrm{~g}$ azoxistrobina ha ${ }^{-1}+24 \mathrm{~g}$ ciproconazol ha ${ }^{-1}$ encontraram resultado superior em dois 
estádios de aplicação R2 e R5.1 obtendo os melhores resultados em produtividade, corroborando com trabalho realizado por Matos et al. (2017) que encontraram resultado semelhante.

O tratamento controle (T01) obteve 150,2 gramas de massa de 1000 grãos, apresentando a menor massa entre os tratamentos (Tabela 3). Os tratamentos fungicidas apresentaram massa de 1000 grãos entre 152,4 (T02) a 170,0 (T04) gramas. O tratamento T04, com massa relativa de grãos de 13,1\%, superou em 19,8 gramas a mais de massa de 1000 grãos em comparação ao tratamento controle T01. O tratamento T04 se destacou por superar não só a tratamento controle sem fungicidas, mas os demais tratamentos fungicidas, considerando dois importantes parâmetros de produção. O tratamento T04 foi superior em relação a produtividade e massa de 1000 grãos (Tabela 3). Este resultado vem de encontro com o proposto pela Syngenta com uso do seu programa de controle de doenças "(Elatus + Cypress + Ochima) $>$ (Cypress + Bravonil 500) > (Cypress + Bravonil 500) com adjuvante Ochima", de maximizar a produtividade de grão na cultura da soja. Resultados semelhantes foram encontrados por Ribeiro et al., (2016).

TABELA 3. Média das variáveis tecnológicas: Altura de planta, Altura de inserção da primeira vagem, Número de vagens por plantas, Peso de mil grãos, Produtividade em quilograma por hectare e População de plantas final em trabalho conduzido pelo Núcleo de Estudo e Pesquisa em Fitotecnia, instalada em uma lavoura comercial de Soja, cultivar Ponta IPRO. Jataí. Estado de Goiás. Safra 2018/2019.

\begin{tabular}{ccccccc}
\hline TRAT & AP $(\mathrm{cm})$ & AIPV $(\mathrm{cm})$ & NVPP & PMG $(\mathrm{g})$ & $\mathrm{P} \mathrm{KG} \mathrm{ha}^{-1}$ & PPF \\
\hline T01 & 58,0 & 12,6 & 30,0 & $150,2 \mathrm{~b}$ & $3318,0 \mathrm{~b}$ & 295.000 \\
T02 & 59,7 & 13,1 & 31,0 & $152,4 \mathrm{~b}$ & $3600,0 \mathrm{a}$ & 296.111 \\
T03 & 58,8 & 13,3 & 30,0 & $153,2 \mathrm{~b}$ & $3438,0 \mathrm{~b}$ & 299.444 \\
T04 & 56,6 & 13,5 & 29,0 & $170,2 \mathrm{a}$ & $3672,0 \mathrm{a}$ & 298.333 \\
\hline CV $(\%)$ & 6,9 & 9,3 & 5,1 & 6,8 & 11,3 & 9,7 \\
\hline
\end{tabular}

Valores sem letra, na coluna, não diferem estatisticamente a $5 \%$ de probabilidade pelo teste de Tukey. TRAT: Tratamentos utilizados, AP: Altura de plantas; AIPV: Altura de inserção de primeira vagem; NVPP: Número de vagens por planta; PMG: Peso de mil grãos; P KG ha ${ }^{-1}$ : Produtividade em quilograma por hectare; PPF: População de plantas final por hectare.

FONTE: Dados da pesquisa, 2019.

Entre os problemas fitossanitários observados pode-se destacar as doenças de final de ciclo (DFC) causadas pelo complexo de patógenos Septoria glycines e ou Cercospora kikuchi (Tabela 4) a ferrugem asiática da soja (FAS), causada por Phakopsora pachyrhizi e a antracnose na folha e na vagem causada por Colletotrichum truncatum (Tabela 5).

O tratamento controle (T01) apresentou maiores níveis de severidade de DFC, isto é, apresentando maiores porcentagens de áreas foliares infectadas (\%AFI), em todas as avaliações realizadas entre 19/12/208 e 05/02/2019, em comparação aos tratamentos com diferentes programas de proteção com fungicidas, programas comumente utilizado pelos produtores da região (T02, T03), com controle inferior ao programa indicado pela Syngenta "(Elatus + Cypress + Ochima) > 
(Cypress + Bravonil 500) > (Cypress + Bravonil 500) com adjuvante Ochima" tratamento (T04), vindo de encontro com a proposta de utilizar a recomendação técnica com suas respectivas doses, propiciando um melhor controle das doenças e uma maior produtividade em sacas por hectare.

Os tratamentos fungicidas (T02, T03, T04) apresentaram menores severidades que 0 tratamento controle (T01) (Tabela 4), entretanto, pode-se destacar o tratamento (T04) este tratamento apresentou menores severidades de DFC não só em relação ao tratamento controle (T01), mas em relação aos demais tratamentos fungicidas (T02, T03), mais uma vez pode-se destacar a eficiência do programa "(Elatus + Cypress + Ochima) $>$ (Cypress + Bravonil 500) $>$ (Cypress + Bravonil 500) com adjuvante Ochima" da Syngenta em relação aos outros tratamento utilizado e tratamento controle, testados nesta pesquisa.

TABELA 4. Média dos índices de severidade representados pelas porcentagens de área foliar infectada (\%AFI) das doenças de final de ciclo (DFC) (Septoria glycines e Cercospora kikuchii) e a evolução da severidade entre as datas 19/12/2018 e 05/02/2019 em trabalho conduzido pelo Núcleo de Estudo e Pesquisa em Fitotecnia, instalada em uma lavoura comercial de Soja, cultivar Ponta IPRO. Jataí. Estado de Goiás. Safra 2018/2019.

\begin{tabular}{|c|c|c|c|c|c|c|}
\hline TRAT & $\begin{array}{c}\text { DFC } \\
19 / 12 / 18 \\
\text { R4 }\end{array}$ & $\begin{array}{c}\text { DFC } \\
07 / 01 / 19 \\
\text { R } 5.2\end{array}$ & $\begin{array}{c}\text { DFC } \\
17 / 01 / 19 \\
\text { R } 5.4\end{array}$ & $\begin{array}{c}\text { DFC } \\
23 / 01 / 19 \\
\text { R } 5.4\end{array}$ & $\begin{array}{c}\text { DFC } \\
30 / 01 / 19 \\
\text { R6 }\end{array}$ & $\begin{array}{c}\text { DFC } \\
05 / 02 / 19 \\
\text { R7 }\end{array}$ \\
\hline T01 & 0,7 & 1,8 & $5,5 \mathrm{~b}$ & $9,3 \mathrm{~b}$ & 10,7 & 9,6 \\
\hline T02 & 0,1 & 0,2 & $1,1 \mathrm{a}$ & $1,1 \mathrm{a}$ & 3,1 & 5,2 \\
\hline T03 & 0,5 & 0,3 & $0,5 \mathrm{a}$ & $0,2 \mathrm{a}$ & 0,8 & 3,1 \\
\hline T04 & 0,0 & 0,1 & $0,3 \mathrm{a}$ & $0,1 \mathrm{a}$ & 0,3 & 1,3 \\
\hline CV (\%) & 3,7 & 4,8 & 8,8 & 7,2 & 9,3 & 4,8 \\
\hline
\end{tabular}

TRAT: Tratamentos utilizados, DFC: Doença de final de ciclo; Estágios de aplicação dos produtos: R2 (plantas no reprodutivo- floração plena); R.5.1 (reprodutivo- fase inicial de enchimento de grãos) e R.5.3 (fase reprodutiva- enchimento de grão de 50 a $70 \%$ ).

FONTE: Dados da pesquisa, 2019.

Dentre os tratamentos utilizados o tratamento controle (T01) apresentou maiores níveis de severidade de ferrugem asiática da soja (FAS) (Tabela 5). Esta doença foi detectada primeiramente no tratamento (T01), em 23/01/2019, contrastando com a DFC, que apareceu mais precocemente. Os tratamentos fungicidas apresentaram severidades de FAS muito próximos, isto é, valores semelhantes entre os tratamentos testados, diferindo com o verificado para a DFC, verificando-se maiores diferenças de severidades entre os tratamentos fungicidas.

Confirmando os resultados anteriores, pode-se destacar o tratamento (T04) “ (Elatus + Cypress + Ochima) $>$ (Cypress + Bravonil 500) $>$ (Cypress + Bravonil 500) com adjuvante Ochima" indicado pela Syngenta, não foi detectado FAS em nenhuma avaliação (Tabela 5), o que demonstra seu efetivo controle da doença e propiciando uma maior produtividade sem sacas por hectare, objetivo do tratamento fúngicos proposto. Resultados semelhantes foram encontrados por Ribeiro et al., (2016) e Matos et al., (2017). Com a mesma linha de raciocínio o trabalho realizado por Silva et al., (2007) chegou à conclusão que o fungicida triazol (cyproconazole) e sua mistura com o fungicida estrobilurina (azoxystrobina + cyproconazole) apresentam eficiente controle da ferrugem asiática, trabalhando com diferentes variedades de 
soja. A antracnose na folha causada por Colletotrichum truncatum apresentou baixo nível de incidência e severidade nas plantas e a antracnose na vagem e nível de desfolhas não apresentou nenhum índice de incidência e severidade (Tabela 5). Em trabalho realizado por Ribeiro et al. (2016) foi registrado resultado semelhante ao encontrado nesta pesquisa.

TABELA 5. Médias dos índices da evolução de severidade representados pelas porcentagens de área foliar infectada (\%AFI) das doenças FAS, AF e NDF sob condições de campo, entre as datas 19/12/2018 a 05/02/2019 em trabalho conduzido pelo Núcleo de Estudo e Pesquisa em Fitotecnia, instalado em uma lavoura comercial de Soja, cultivar Ponta IPRO. Jataí. Estado de Goiás. Safra 2018/2019.

\begin{tabular}{|c|c|c|c|c|c|c|c|c|}
\hline TRAT & $\begin{array}{c}\text { FAS } \\
23 / 01 / 19 \\
\text { R } 5.5\end{array}$ & $\begin{array}{c}\text { FAS } \\
30 / 01 / 1 \\
9 \\
\text { R } 5.5 \\
\end{array}$ & $\begin{array}{c}\text { FAS } \\
05 / 02 / 19 \\
\text { R5.5 }\end{array}$ & $\begin{array}{c}\text { AF } \\
30 / 01 / 1 \\
9 \\
\text { R } 5.5 \\
\end{array}$ & $\begin{array}{c}\mathrm{AF} \\
05 / 02 / 19 \\
\text { R5.5 }\end{array}$ & $\begin{array}{c}\text { AV } \\
05 / 02 / 1 \\
9 \\
\text { R5.5 } \\
\end{array}$ & $\begin{array}{c}\text { NDF } \\
23 / 01 / 19 \\
\text { R } 5.5\end{array}$ & $\begin{array}{c}\text { NDF } \\
05 / 02 / 1 \\
9 \\
\text { R5.5 } \\
\end{array}$ \\
\hline T01 & 0,3 & 1,3 & 3,6 & 7,3 & $5,2 \mathrm{a}$ & 0,0 & 25,0 & 80,0 \\
\hline T02 & 0,0 & 0,0 & 0,1 & 6,3 & $3,1 \mathrm{a}$ & 0,0 & 10,0 & 75,0 \\
\hline T03 & 0,0 & 0,0 & 0,2 & 8,3 & $10,4 \mathrm{~b}$ & 0,0 & 15,0 & 75,0 \\
\hline T04 & 0,0 & 0,0 & 0,0 & 9,4 & $7,3 \mathrm{a}$ & 0,0 & 15,0 & 75,0 \\
\hline $\begin{array}{l}\text { CV } \\
(\%)\end{array}$ & 0,2 & 1,9 & 8,3 & 10,2 & 13,2 & 18,3 & 6,3 & 3,8 \\
\hline
\end{tabular}

FONTE: Dados da pesquisa, 2019.

\section{CONCLUSÃO}

Programas de proteção fungicida proporcionaram rendimento de grãos superiores quando comparado ao tratamento sem proteção fungicida. Para programas fungicidas mais efetivos, esta superioridade foi situada em produtividade relativa de $10,6 \%$ a mais, com $354 \mathrm{Kg} \mathrm{ha}^{-1}$ a mais quando comparado ao tratamento controle.

O programa de proteção fungicida com a sequência de pulverizações: (Elatus + Cypress + Ochima) > (Cypress + Bravonil 500) > (Cypress + Bravonil 500) proporcionaram maiores rendimentos de grãos e proporcionaram maiores eficiências de controle de doenças de final de ciclo (DFC) (Cercospora kikuchi e Septoria glycines) e de ferrugem asiática da soja (FAS) (Phakopsora pachyrhizi).

\section{AGRADECIMENTOS}

Ao Núcleo de Estudo e Pesquisa em Fitotecnia por contribuir com informações técnicas para condução do projeto e aos funcionários da EMATER de Jataí por contribuir com mão de obra especializada. A todos os acadêmicos do curso de Agronomia pela participação no desenvolvimento deste projeto.

\section{REFERÊNCIAS}


AGRITEMPO - Sistema de Monitoramento Agrometeorológico Mineiros / INMET. Município de Mineiros, Estado de Goiás. 2018. Disponível em: $<$ http://agrometeorologia.seagro.to.gov.br/rede-de-monitoramento/inmet/> Acessado: 01 de janeiro de 2019.

CONAB. Companhia Nacional de Abastecimento. Acompanhamento da safra brasileira - grãos, Safra 2018/19 - Quarto levantamento, Brasília. v. 6. p. 1-126, 2019. ISSN 2318-6852. Disponível em: <https://www.conab.gov.br/infoagro/safras/graos> Acessado em: 26 de janeiro de 2019.

EMBRAPA. Centro Nacional de Pesquisa de Soja. Tecnologias de produção de soja - região central do Brasil, Londrina: Embrapa Soja,- (Sistemas de Produção / Embrapa Soja, 2013a. n.16, p.265, 2014. ISSN 2176- 2902. Disponível em: $<$ https://ainfo.cnptia.embrapa.br/digital/bitstream/item/95489/1/SP-16-online.pdf> Acessado em 23 de janeiro de 2019.

EMBRAPA. Empresa Brasileira de Pesquisa Agropecuária. Sistema Brasileiro de Classificação de Solos. Brasília, 3ª̣ edição, p.353, 2013b. ISBN 978-85-7035-1982.

GODOY, C.V; KOGA, L.J; CANTERI, M.G. Diagrammatic scale for assessment of soybean rust severity. Fitopatologia Brasileira, v.31, p.63-68. 2006. Disponível em: $<\quad$ http://www.scielo.br/scielo.php?script=sci_arttext\&pid=S010041582006000100011 > Acessado em 20 de janeiro de 2019.

GODOY, C. V; FLAUSINO, A. M; SANTOS, L. C. M; PONTE, E. M. D; Eficiência do controle da ferrugem asiática da soja em função do momento de aplicação sob condições de epidemia em Londrina, PR. Tropical Plant Pathology, v. 34, p. 56-61, 2009. ISSN 1983-2052, Disponível em: <http://www.scielo.br/pdf/tpp/v34n1/a11v34n1>

GODOY, C.V.; SEIXAS, C.D.S.; SOARES, R. M.; MARCELINOGUIMARAES, F.C.; MEYER, M.C.; COSTAMILAN, L.M. Asian soybean rust in Brazil: past, present, and future. Pesquisa Agropecuária Brasileira, v. 51, p. 407-421, 2016. http://dx.doi.org/10.1590/S0100-204X2016000500002 Disponível em: <http://www.scielo.br/scielo.php?script=sci_arttext\&pid=S0100204X2016000500407> Acessado em 20 de janeiro de 2019.

GRIGOLLI, J. F. J; GRIGOLLI, M. M. K. Manejo de Doenças na Cultura da Soja. Tecnologia e Produção: Soja 2017/2018. p.1-15, 2018. Disponível em: $<$ http://www.fundacaoms.org.br/base/www/fundacaoms.org.br/media/attachments/30 3/303/5bf01cc3a7885009c9e47176f153fe5e967c6cb20f243_06-manejo-de-doencasna-cultura-da-soja-somente-leitura.pdf> Acessado em 14 de maio de 2019.

HIRANO, M.; HIKISHIMA; SILVA, A. J.; XAVIER, S.A.; GIOVANETTI, C. Validação de escala diagramática para estimativa de desfolha provocada pela ferrugem 
asiática em soja. Summa Phytopathologica, v. 36, n. 3, p. 248-250, 2010. Disponível em: < http://www.scielo.br/scielo.php?script=sci_arttext\&pid=S0100$54052010000300012>$ Acessado em 16 de janeiro de 2019.

KÖPPEN, G; ALVARES, C.A; STAPE, J.L; SENTELHAS, P.C; DE GONÇALVES, M; LEONARDO, J; GERD, S; Köppen's Climate Classification Map for Brazil. Meteorologische Zeitschrift, p.711-728, 2013. DOI: https://doi.org/10.1127/09412948/2013/0507

MATOS, F. S. A; ALMEIDA JÚNIOR, J. J; SMILJANIC, K. B. A. Eficiência de fungicidas para o controle da ferrugem asiática da soja (Phakopsora pachyrhizi), safra 2015/2016. I Colóquio Estadual de Pesquisa Multidisciplinar. v. 1, p. 1-10, 2016. ISSN 2527-2500, Disponível em: <http://publicacoes.unifimes.edu.br/index.php/coloquio/article/view/24> Acessado em 10 de fevereiro de 2019.

MATOS, F. S. A; ALMEIDA JÚNIOR, J. J; SMILJANIC, K. B. A; MENDONÇA, A. F. MARTINS FILHO; M. B. SILVA. A. R. Fungicida cronnos para o manejo químico das doenças da soja, a campo, em Jataí - GO, safra agrícola 2016/2017. II Colóquio Estadual de Pesquisa Multidisciplinar, v. 2, p. 1-12, 2017. ISSN 2527-2500, Disponível em: <http://publicacoes.unifimes.edu.br/index.php/coloquio/article/view/231> Acessado em 12 de fevereiro de 2019.

RAIJ, B. V; ANDRADE, J.C.; CANTARELLA, H.\& QUAGGIO, J.A. (Ed.). Análise química para avaliação da fertilidade de solos tropicais. Campinas: Instituto agronômico, p.285, 2001. Disponível em: <https://www.bdpa.cnptia.embrapa.br/consulta/busca?b=ad\&id=14135\&biblioteca=C NPSO\&busca=autoria:\%22RAIJ,\%20B.\%20van.\%22\&qFacets=autoria:\%22RAIJ,\%2 0B.\%20van.\%22\&sort=\&paginacao=t\&paginaAtual=1>

RIBEIRO, F. C; ERASMO, A. L; MORAES, E. B; CERQUEIRA, F. B; MATOS, E. P; ROCHA, F. S. Fungicidas aplicados na cultura da soja visando o controle da ferrugem asiática no estado do Tocantins. Revista Cultivando o Saber, v. 9, p.198209, 2016. ISSN 2175-2214, Disponível em: <https://www.fag.edu.br/upload/revista/cultivando_o_saber/57a3b0899b617.pdf> Acessado em 15 de janeiro de 20

YORINORI, J. T.; PAIVA, W. M.; COSTAMILAN, L. M.; BERTAGNOLLI, P. F. 19.

Ferrugem da Soja: identificação e controle. Londrina: Embrapa Soja. Comunicado Técnico, p. 25, 2003. Disponível em: <https://ainfo.cnptia.embrapa.br/digital/bitstream/item/59588/1/Documentos-204.pdf> Acessado em 14 de janeiro de 2019. 
SILVA, V. A. S; JULIATTI, F. C; SILVA, L A. S. Interação entre resistência genética parcial e fungicidas no controle da ferrugem asiática da soja. Pesquisa Agropecuária Brasileira, v. 42, n. 9, p.1261-1268, 2007. ISSN 1678-3921.

SOARES, R. M; GODOY, C. V; OLIVEIRA, M. C. N. Escala diagramática para avaliação da severidade da mancha alvo da soja. Tropical PlantPathology, v. 34, n. 5, p. 333-338, 2009. Disponível em: <http://www.scielo.br/pdf/tpp/v34n5/v34n5a07.pdf> Acessado em 31 de janeiro de 2019. 